\title{
Effect of Abrasive Grinding on the Strength and Reliability of Alumina
}

\author{
W. H. Tuan* and J. C. Kuo \\ Institute of Materials Science and Engineering, National Taiwan University, Taipei, 10764, Taiwan
}

(Received 13 August 1997; accepted 7 November 1997)

\begin{abstract}
In the present study, the effect of depth of cut during abrasive grinding on the strength and reliability of alumina is investigated. The reliability is expressed in terms of Weibull modulus. The alumina specimens were prepared by die-pressing and sintering. Large flaws are formed in the surface region during diepressing. The strength and reliability of the as-sintered alumina specimens are improved after abrasive grinding. The improvement is contributed by the change of flaw size distribution and the introduction of residual stresses during grinding. As the depth of cut is less than $10 \mu$ mpass $^{-1}$, large surface flaws are either removed or reduced in size. The grinding process can induce residual stresses near surface. The presence of the residual stresses enhances the average strength of alumina by roughly $30 \mathrm{MPa}$. As the depth of cut is increased to $20 \mu \mathrm{mpass}^{-1}$, many machining flaws are formed in the surface region. The average strength and Weibull modulus are then decreased. Due to the formation of many surface cracks, residual stresses are released. Therefore, there is no contribution from residual stresses to the strength of the specimens ground with large depth of cut. (C) 1998 Elsevier Science Limited. All rights reserved
\end{abstract}

\section{Introduction}

For structural applications, dimensional tolerance has to be tightly controlled. Abrasive grinding is therefore frequently applied to match the requirement. Due to the hardness of ceramics being high and the toughness low, grinding is not only a difficult but also an expensive process. ${ }^{1,2}$ Due to the importance of the grinding process, considerable research activities have been focused on it. ${ }^{3-19}$

*To whom correspondence should be addressed.
Several conclusions can be drawn from previous studies.

- The grinding process can generate surface flaws. ${ }^{3-10}$ The size of the flaws depends strongly on the microstructure of ceramic. The size of machining flaws increases with increasing grain size..$^{7-10}$

- The grinding process can induce residual stresses near surface region. ${ }^{6,17-19}$ The presence of residual stresses affects the resulting strength.

- The residual stresses can be modified by applying annealing treatment. ${ }^{6}$ However, the flaw size may also be changed during annealing. Therefore, the contribution from residual stresses to the strength is difficult to quantify by annealing study alone. ${ }^{20}$

Previous studies suggested that flaws are produced during the grinding process. However, many flaws are in the ceramic components before the components are machined. Therefore, there are two types of flaws that are formed at different stages. One type of flaw is related to the powder characteristics, forming techniques and contamination. This type of flaw can be termed as a processing flaw. The other type of flaw is generated during grinding. This type of flaw can be termed as a machining flaw. Two types of flaw are formed in sequence. The size distribution of processing flaws can be altered by grinding.

Large machining flaws are formed as improper grinding parameters are used. ${ }^{3-10}$ The flaw size distribution in the fired components may also be broadened. As the flaw size is widely distributed, the strength is varied significantly from one component to another one. The reliability is thus low. The flaw size distribution thus underlines the reliability of the ceramic components. For structural applications, both high strength and high reliability are essential. 
Ceramic is fractured in a brittle manner. The fracture originates from the critical flaw on the surface or in the interior of the component. The reliability of ceramic components can thus be characterized with Weibull statistics. As the Weibull modulus is high, the distribution of strength is narrow. The reliability is thus high. Until now, less attention has been given to the effect of grinding on reliability.

The grinding process can also induce residual stresses near surface. ${ }^{6,17-20}$ The change of flaw size and the presence of residual stresses all affect the resulting strength. However, these two effects are frequently mixed together. ${ }^{20}$ In the present study, the effects of the flaw size change and of the residual stresses on strength are investigated with different approaches. The role of each effect on strength and reliability can then be evaluated separately.

In the present study, three issues are addressed. These issues are:

- the interactions between processing flaws and machining flaws;

- the effect of the interactions on the reliability of ceramics;

- the contribution of residual stresses to the strength after grinding.

\section{Experimental}

A spray-dried alumina powder ( AL-160SG-3, $99.5 \% \quad \mathrm{Al}_{2} \mathrm{O}_{3}$, mean size of $\mathrm{Al}_{2} \mathrm{O}_{3}$ particles $=0.6 \mu \mathrm{m}$, mean size of spray dried granules $=80 \mu \mathrm{m}$, Showa Aluminum Industries, Tokyo, Japan) was used in the present study. The specimens were prepared by die-pressing the powders into rectangular bars. The pressing pressure employed was $140 \mathrm{MPa}$. The $\mathrm{Al}_{2} \mathrm{O}_{3}$ compacts were sintered at $1600^{\circ} \mathrm{C}$ for $1 \mathrm{~h}$. After firing, the size of the rectangular bars was $3.2 \times 4.0 \times 44 \mathrm{~mm}$.

Grinding was performed using a surface grinder with a resin bonded 325 grit diamond wheel. The diameter of the wheel was $175 \mathrm{~mm}$. The wheel was first trued by grinding a low-carbon steel. The wheel was then dressed with a porous alumina dressing stick. A water-based oil emulsion grinding fluid was used for cooling purposes. The specimens were ground longitudinally at a table speed of $0.17 \mathrm{~m} \mathrm{~s}^{-1}$ and a wheel surface speed of $27.5 \mathrm{~m} \mathrm{~s}^{-1}$. The depth of cut was varied from 5 to $30 \mu \mathrm{m}$ pass $^{-1}$. The depth of cut was kept constant until $0.2 \mathrm{~mm}$ in thickness of the specimen was removed. More than 28 specimens were used for each grinding conditions.

Some specimens were annealed to remove the residual stresses. These specimens were first ground with $10 \mu \mathrm{mpass}^{-1}$. The annealing took place at $1190^{\circ} \mathrm{C}$ for $1 \mathrm{~h}$ or for $10 \mathrm{~h}$. The extent of residual stresses was determined by the X-ray diffraction (XRD) method $(30 \mathrm{KV}, 20 \mathrm{~mA})$. A thin layer of silicon slurry was coated on the surface of the XRD specimens. The silicon layer was used as an internal standard for the determination of diffraction angle. Three specimens for each grinding condition were used for the XRD analysis. The final density was determined by the water displacement method. The grain boundaries were revealed by thermal etching the polished specimens. The grain size was determined using the linear intercept technique. More than 300 grains were counted. Four-point bending technique was used to determine the flexural strength of the specimens. The four-point span was $10 \mathrm{~mm} \times 30 \mathrm{~mm}$. The rate of loading was $0.083 \mathrm{~mm} \mathrm{~s}^{-1}$. A dye was applied to the testing bars before the measurement of strength. The specimens were then dried in an oven at $40^{\circ} \mathrm{C}$ for $24 \mathrm{~h}$. After fracture, the fracture surface was observed with a stereo optical microscope to identify the presence of large surface flaws. The surface roughness of the ground surfaces was measured with a stylus surface profilometer. For each grinding conditions, 15 specimens were used. More than three measurements were taken from one specimen. The microstructure of the ground surfaces was observed with scanning electron microscopy (SEM).

\section{Results and Discussion}

The average density of the as-sintered specimens is $3.91 \mathrm{~g} \mathrm{~cm}^{-3}$. It corresponds to $98 \%$ of the theoretical density. The mean size of alumina grains after sintering is $1.9 \mu \mathrm{m}$. The maximum grains observed is $25 \mu \mathrm{m}$.

An optical micrograph of the fracture surface of a specimen is shown in Fig. 1. Large surface flaws are revealed by the penetration of the dye. The

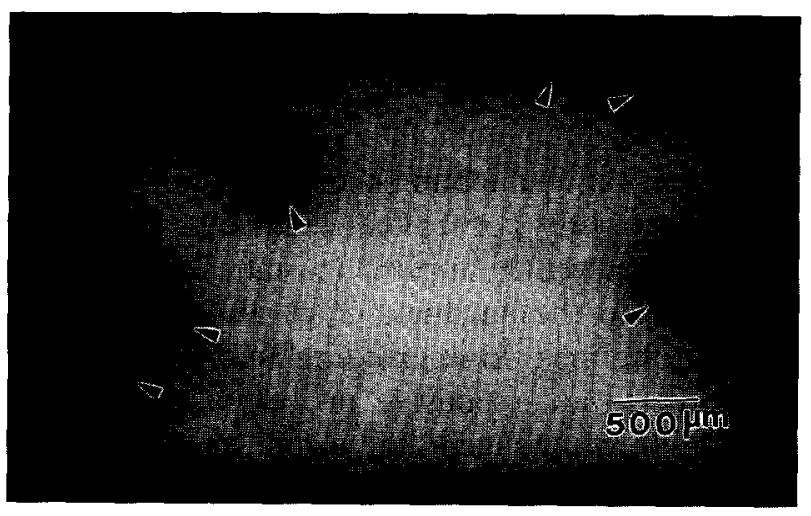

Fig. 1. The optical micrograph of a fracture surface. The large surface flaws are indicated with arrows. 
alumina powder used in the present study was spray-dried first to facilitate the die-pressing. The surface of the spray dried granules was slightly sticky after storage for some time. The granules stuck to the surface of the steel die during pressing. Surface flaws are therefore formed after dic-prcssing. The resolution of the stereo optical microscope is low. Therefore, only the surface flaws with the dimension larger than roughly $200 \mu \mathrm{m}$ (indicate by arrows in Fig. 1) are observed. These flaws are termed as 'large' surface flaws. The large surface flaws are found in $73 \%$ of the as-sintered specimens. In another $27 \%$ of the as-sintered specimens, there may be no surface flaws or the size of surface flaws is smaller than the resolution of the optical microscope. It seems more likely to be the latter case.

The ground surfaces of the specimens are shown in Fig. 2. A small amount of smooth area is observed on the surface. The amount of the smooth area is decreased with the increase of depth of cut. There are many pullouts on the surfaces. The microstructural features are very similar to the observation reported by $\mathrm{Xu}$ et al. on their highpurity alumina specimens. ${ }^{10}$ The material removal mechanism is suggested as grain disintegration that resulted from intergranular microfractures. The surface roughness of the specimens is shown in Fig. 3. The roughness of the as-sintered specimens can be significantly reduced by the surface grinding. However, as the depth of cut is in the range of 5 to $30 \mu \mathrm{m} \mathrm{pass}^{-1}$, the depth of cut has little influence on the surface roughness.

In the present study, the variation of strength is characterized in terms of Weibull two-parameter statistics as

$$
\ln \{\ln [1 /(1-F)]\}=m \ln \sigma-m \ln \sigma_{0}+\text { constant }
$$

In the above equation, $\sigma$ is the strength of the specimen, $\sigma_{0}$ the characteristic strength which corresponds to $63.2 \%$ probability of failure, and $m$ the Weibull modulus. $F$ is the probability of failure which is calculated using the following equation as

$$
F=(n-0 \cdot 5) / N
$$

In the equation, $n$ is the $n$th specimen as the experimental data are ranked in order, and $N$ the total number of specimens.

By using the least-square regression analysis, the value of Weibull modulus can be determined. The scatter in the estimates for the Weibull modulus depends strongly on the number of specimens used $^{21}$ and number of flaw types in the specimens. ${ }^{22}$ The flaw type in the as-sintered specimens

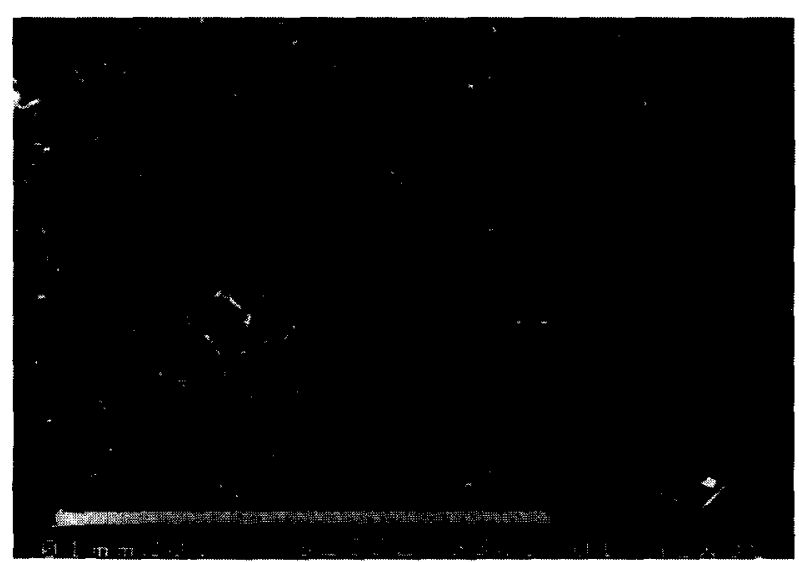

(a)

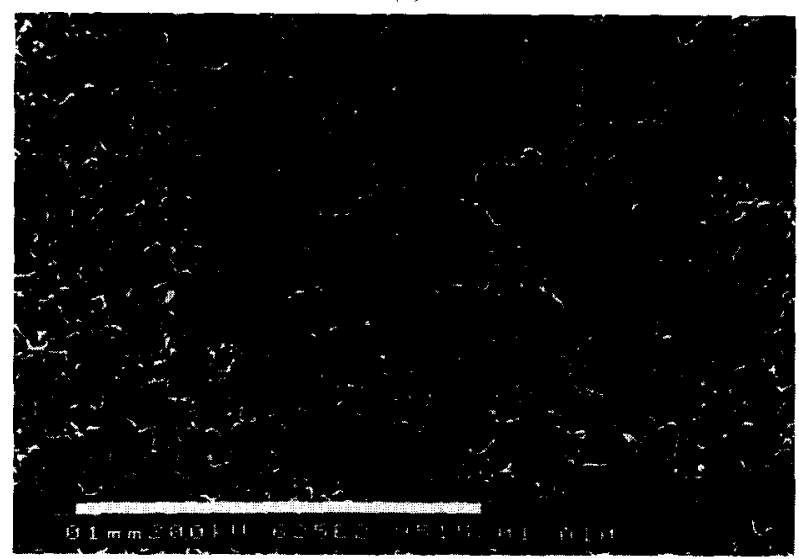

(b)

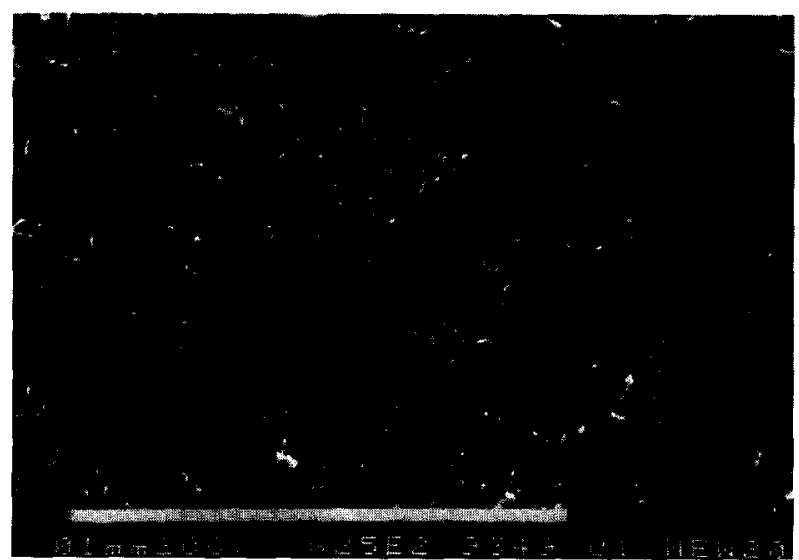

(c)

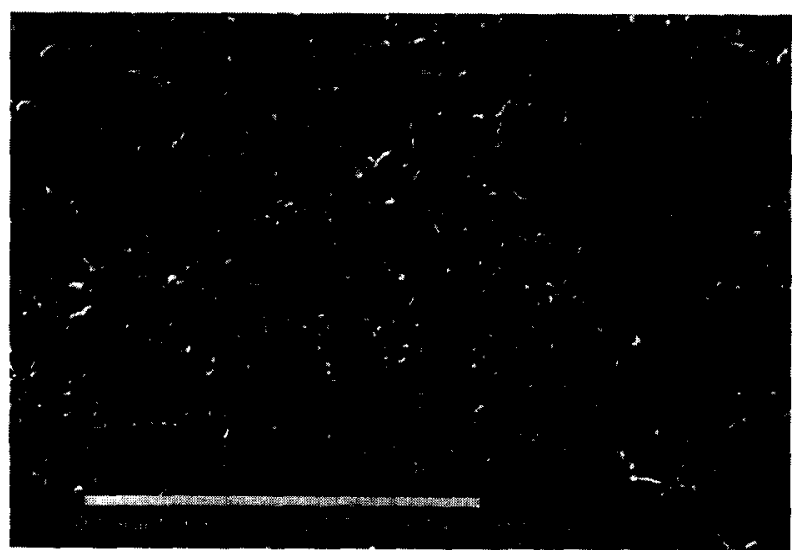

(d)

Fig. 2. The SEM micrographs of the ground surfaces. The depth of cut is (a) 5 , (b) 10 , (c) 20 and (d) $30 \mu \mathrm{m}$ pass $^{-1}$. 
is mainly surface flaw. Furthermore, the abrasive grinding process can only induce flaws in the surface region..$^{3-10}$ Therefore, the flaw type of the assintered and ground specimens is very similar. The Weibull two-parameter statistics can thus be used to analyze the strength distribution.

The scatter of the Weibull modulus can be expressed in terms of the coefficient of variation, $\mathrm{CV}$, as

$$
\mathrm{CV}=(\text { standard deviation }) /(\text { mean value })
$$

Ritter et al. had used a Monte Carlo simulation technique to estimate the values of CV. ${ }^{21}$ Their analysis indicated that the value of $\mathrm{CV}$ is decreased with the increase of the number of specimens. As 30 specimens are used, the value of $\mathrm{CV}$ is 0.18 . It suggests that as the Weibull modulus is 10 , the standard deviation for the modulus is 1.8. Ritter et $a l$. also suggested that the $90 \%$ confidence level for 30 specimens is $2 \cdot 3 .{ }^{21}$ There are 28 to 46 specimens used for each grinding and annealing conditions.

The Weibull distribution for the specimens is shown in Fig. 4. The specimens are ground with different depth of cut. The Weibull distribution for the as-sintered specimens is also shown for comparison. The average strength and the Weibull modulus of the specimens are shown as a function

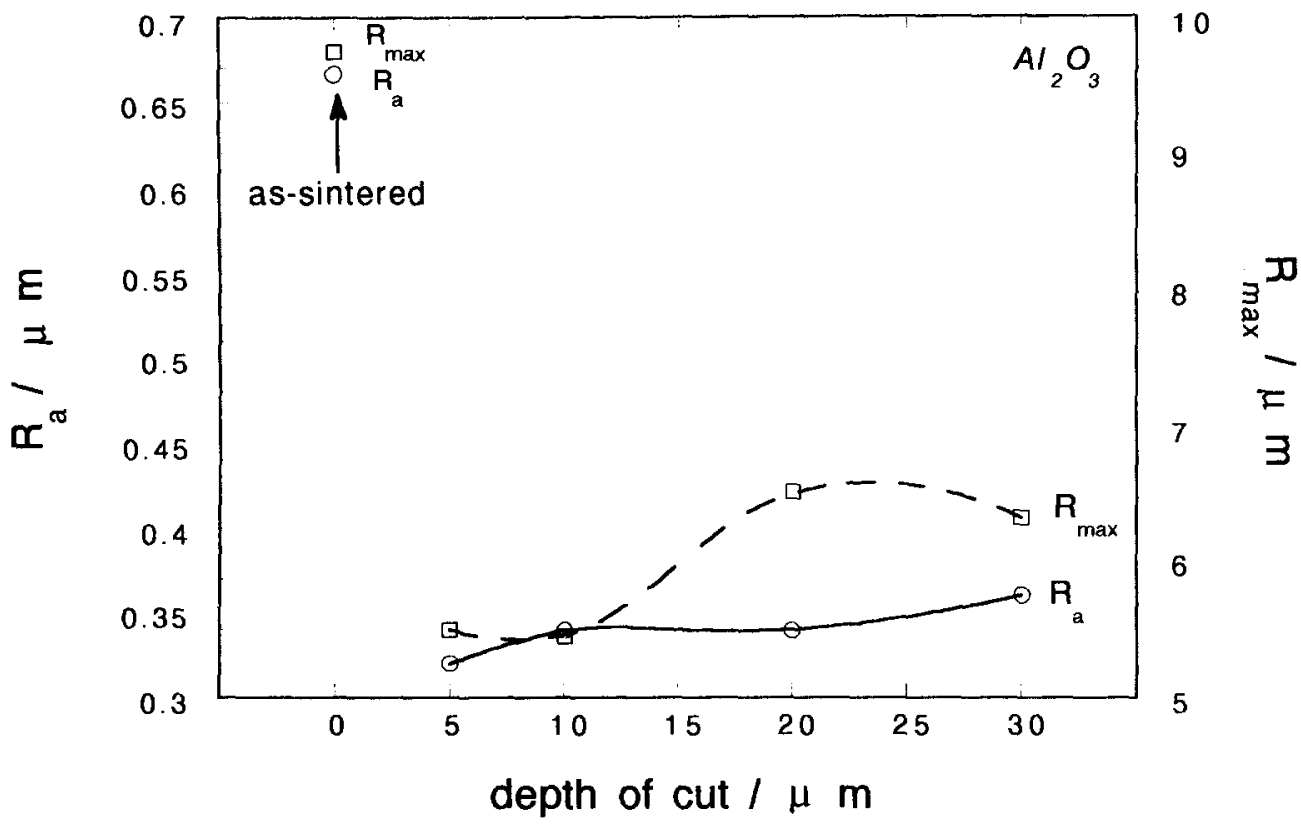

Fig. 3. The surface roughness of the $\mathrm{Al}_{2} \mathrm{O}_{3}$ specimens as a function of depth of cut. The surface roughness of the as-sintered specimens is also shown.

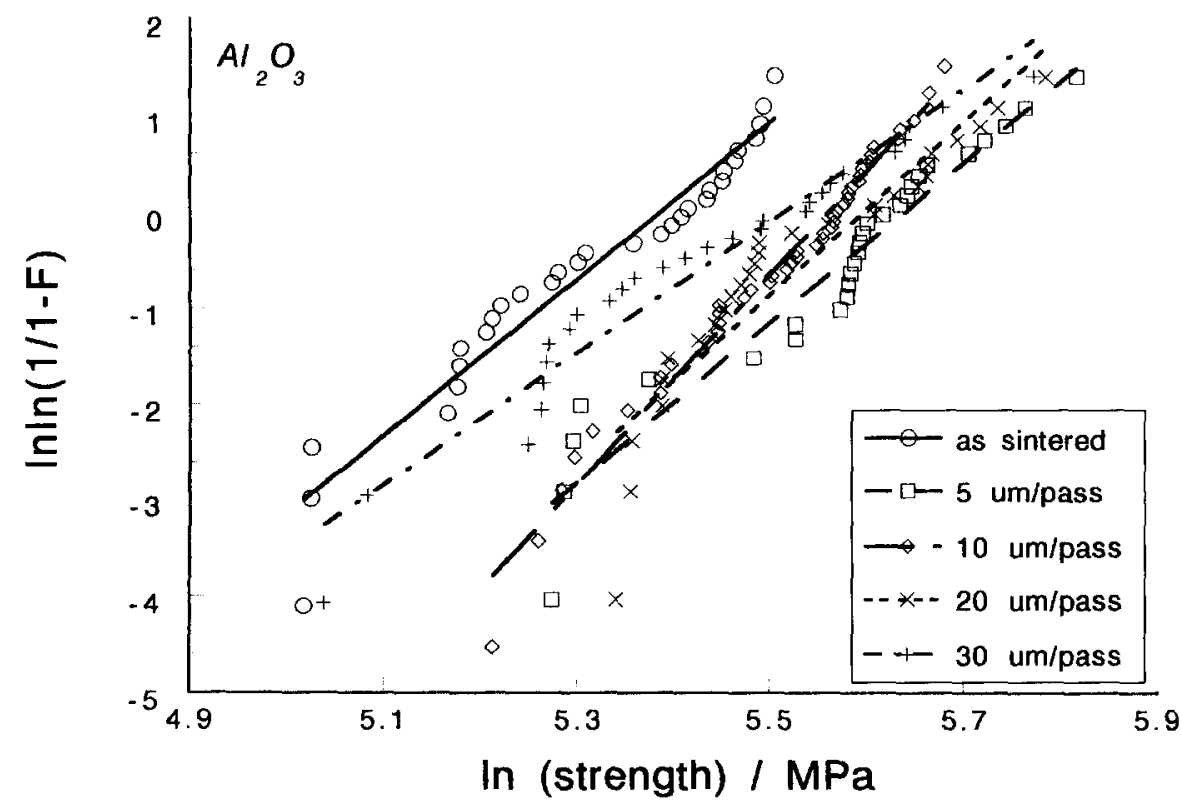

Fig. 4. The Weibull curves for the $\mathrm{Al}_{2} \mathrm{O}_{3}$ specimens before and after grinding. 
of depth of cut in Figs 5 and 6, respectively. Each datum in Fig. 5 is the average value. The error bars show one standard deviation. The average strength is increased by 30 to $60 \mathrm{MPa}$ after grinding. For the ground specimens, the strength is decreased with the increase of the depth of cut. The Weibull modulus follows a similar trend with that of average strength. The Weibull modulus of the as-sintered specimens is increased by 3 as the depth of cut is $10 \mu \mathrm{m}_{\text {pass }}^{-1}$. The increase of the Weibull modulus is larger than the expected standard deviation and the $90 \%$ confidence level. It indicates that the Weibull modulus is improved by grinding with small depth of cut.
For the as-sintered specimens, the size of critical flaws is widely distributed. Furthermore, some large flaws are presented in the surface region. As the specimens are abrasive ground, the large surface flaws in the as-sintered specimens can be removed or reduced in size. The grinding process can thus reduce the size of surface flaws. Therefore, the average strength of the ground specimens is higher than that of as-sintered specimens. Furthermore, due to the flaw size distribution being narrowed, the Weibull modulus is increased. The reliability of the specimens is thus improved. As the specimens were ground with $30 \mu \mathrm{mpass}^{-1}$, large processing flaws near surface can still be

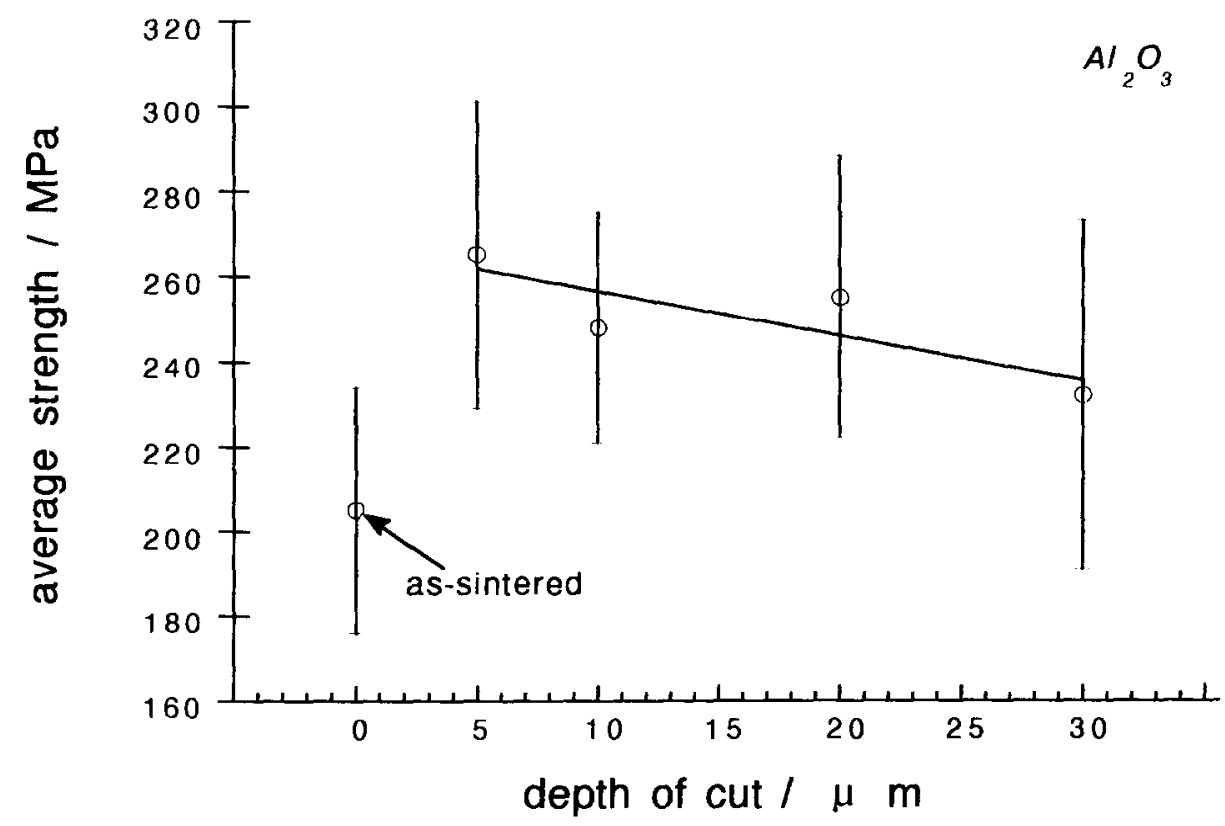

Fig. 5. The average strength of the $\mathrm{Al}_{2} \mathrm{O}_{3}$ specimens as a function of depth of cut.

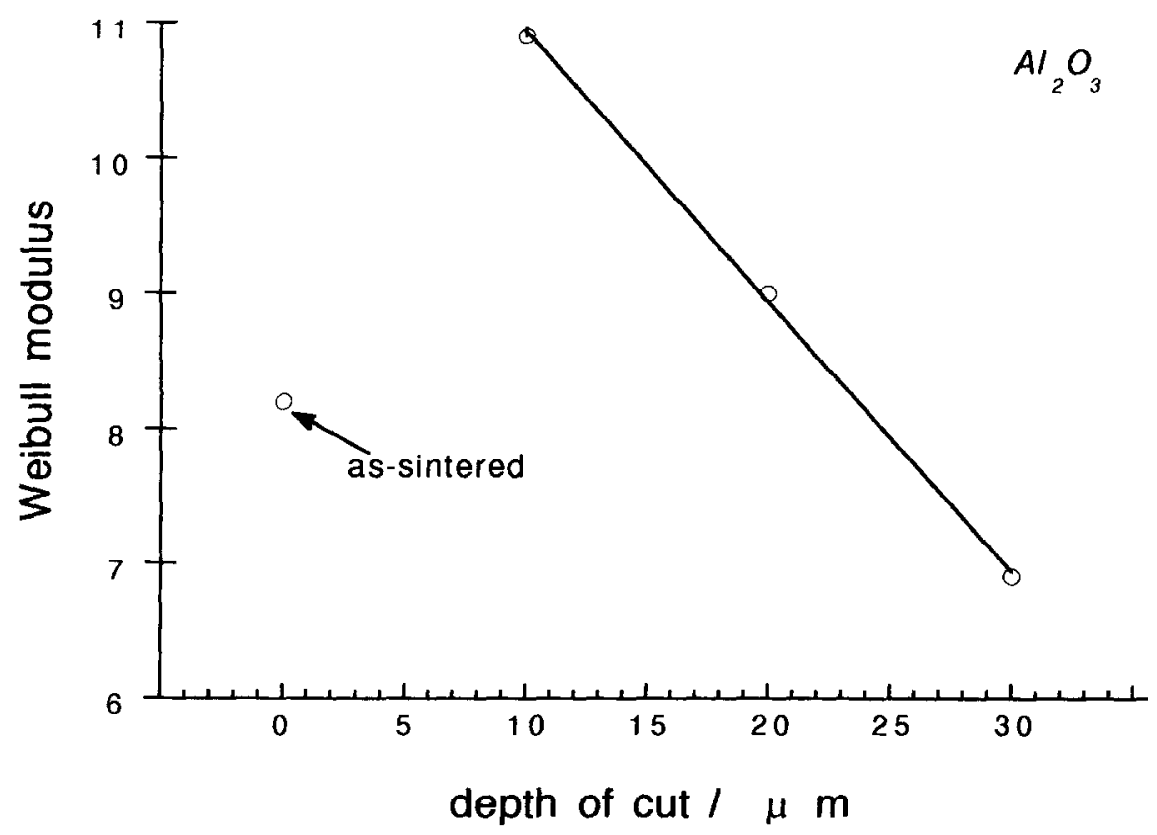

Fig. 6. The Weibull modulus of the $\mathrm{Al}_{2} \mathrm{O}_{3}$ specimens as a function of depth of cut. 
removed or reduced in size. However, the larger depth of cut induces higher local contact force. ${ }^{12}$ The high contact force generates large machining cracks. The average strength and Weibull modulus are therefore decreased as large depth of cut is applied, Figs 5 and 6.

The amount of residual stresses near the surface can be related to the shift of X-ray diffraction angle. ${ }^{23}$ The shift of $2 \theta$ of the (110) peak of $\mathrm{Al}_{2} \mathrm{O}_{3}$ is shown as a function of depth of cut in Fig. 7. For the specimens ground with 5 and $10 \mu \mathrm{m}_{\text {pass }}{ }^{-1}$, the shift of $2 \theta$ is much higher than that of the specimens ground with 20 and $30 \mu \mathrm{m}_{\text {pass }}{ }^{-1}$. It suggests that the residual stresses are presented in the specimens ground with 5 and $10 \mu \mathrm{mpass}^{-1}$. The strength of the specimens ground with 5 and $10 \mu \mathrm{mpass}^{-1}$ is therefore enhanced. There are many grinding flaws formed in the specimens ground with 20 and $30 \mu \mathrm{mpass}^{-1}$. The presence of many grinding flaws releases the residual stresses.

For the specimens ground with 5 or $10 \mu \mathrm{m}_{\text {pass }}{ }^{-1}$, the strength is 40 to $60 \mathrm{MPa}$ higher than that of as-sintered specimens, Fig. 5. The strength enhancement is contributed by the flaw size reduction and the presence of residual stresses. There is no contribution from residual stress to the strength of the specimens ground with 20 and $30 \mu \mathrm{m} \mathrm{pass}^{-1}$ as shown in Fig. 7. The strength of the specimens ground with 5 and $10 \mu \mathrm{mpass}^{-1}$ is around $30 \mathrm{MPa}$ higher than that of the specimens

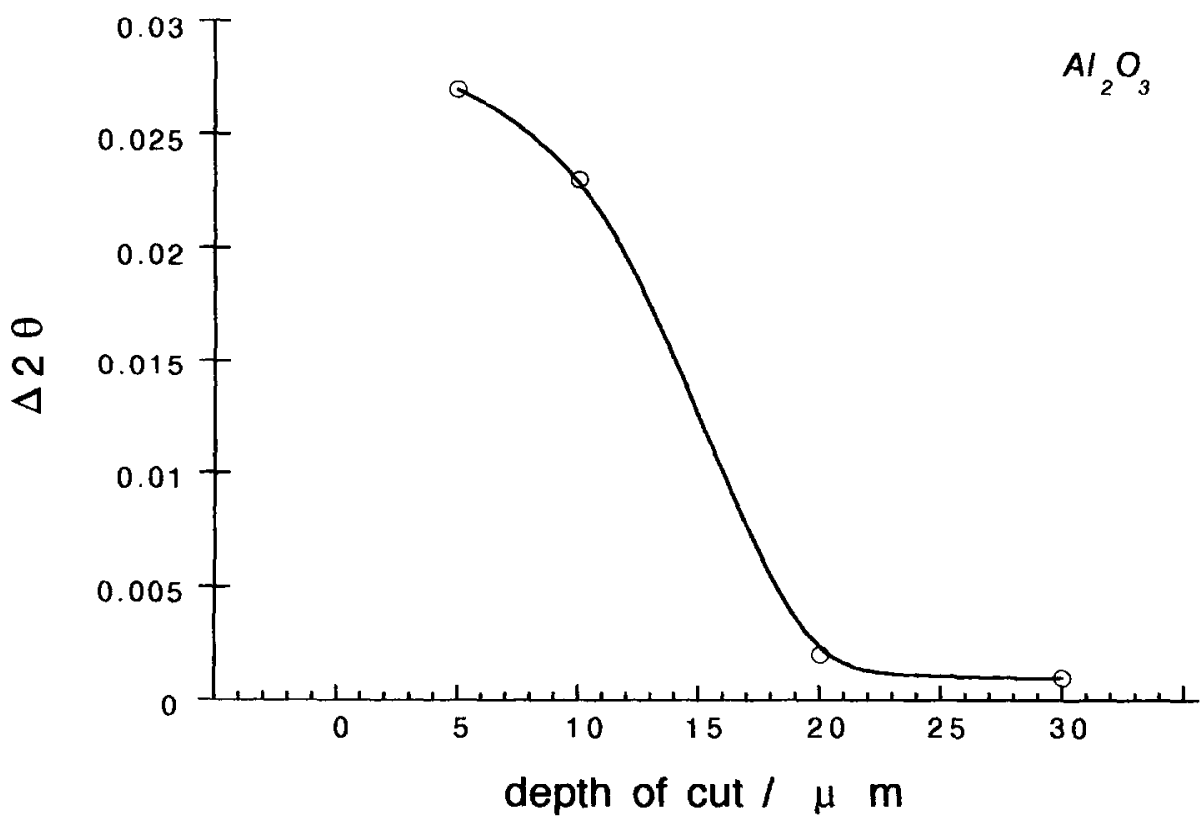

Fig. 7. The shift of X-ray diffraction angle as a function of depth of cut.

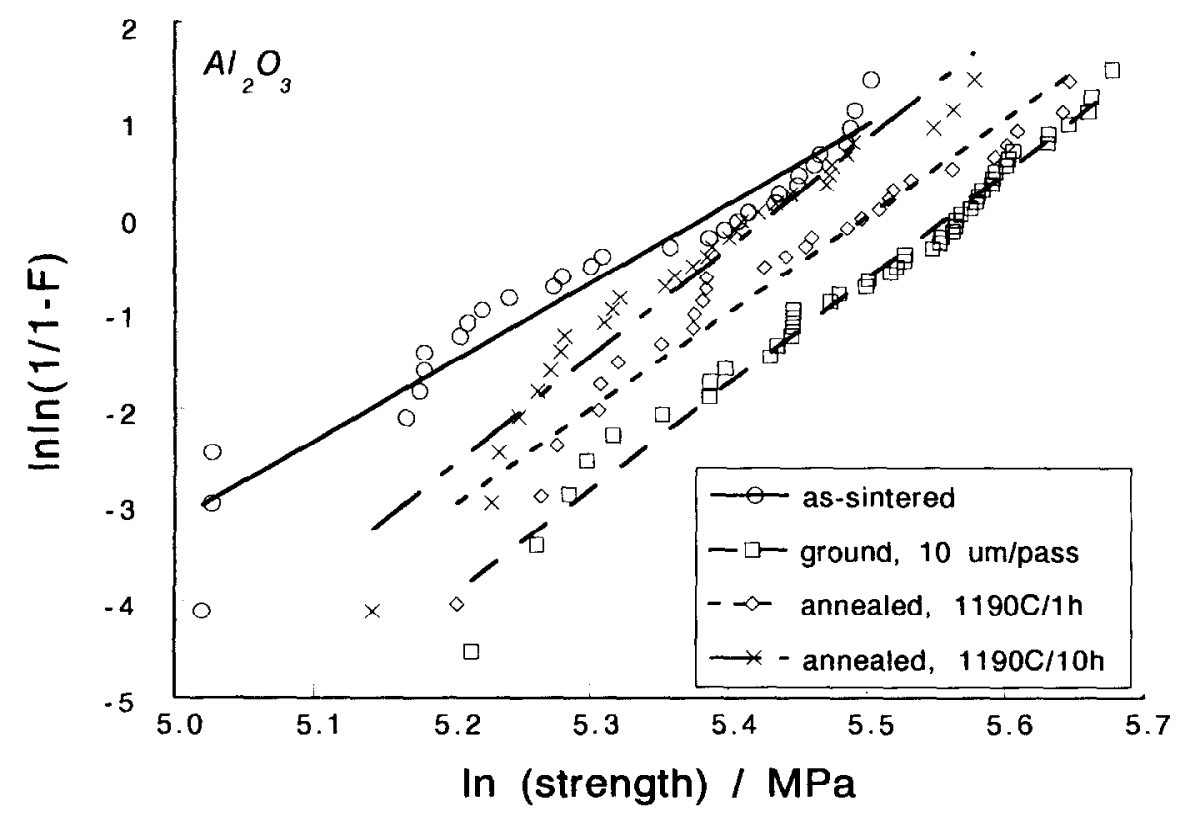

Fig. 8. The Weibull curves for the $\mathrm{Al}_{2} \mathrm{O}_{3}$ specimens before and after annealing at $1190^{\circ} \mathrm{C}$. 
ground with 20 and $30 \mu \mathrm{m}$ pass $^{-1}$ (Fig. 5). Therefore, around $30 \mathrm{MPa}$ strength enhancement is contributed by the presence of residual stresses. Another 10 to $30 \mathrm{MPa}$ strength enhancement is contributed from flaw size reduction.

The residual stress induced by grinding is a function of the distance from the surface. The residual stress is compressive near the surface and tensile underneath. ${ }^{20}$ The penetration of X-ray into alumina is in the range of $10 \mu \mathrm{m} .^{23}$ The information shown in Fig. 7 is therefore limited to the compressive stress layer. The size of critical flaw is bigger than the X-ray penetration depth. The stress state near the crack tip is thus not revealed by the XRD technique. In the present study, by combin- ing the flaw size distribution analysis and XRD analysis, the contribution of residual stress to strength after grinding can be quantified.

The Weibull distribution for the annealed specimens is shown in Fig. 8. The Weibull distribution for the as-sintered and ground specimens is also shown for comparison. The average strength and Weibull modulus for the specimens are shown in Figs 9 and 10, respectively. Annealing process can reduce the residual stress. ${ }^{6,20}$ The average strength of the ground specimens is thus reduced after annealing. However, the process can also change the flaw size distribution by crack healing $20,24,25$ or crack opening. ${ }^{26}$ The effect of annealing process on crack healing or opening is still contradictory.

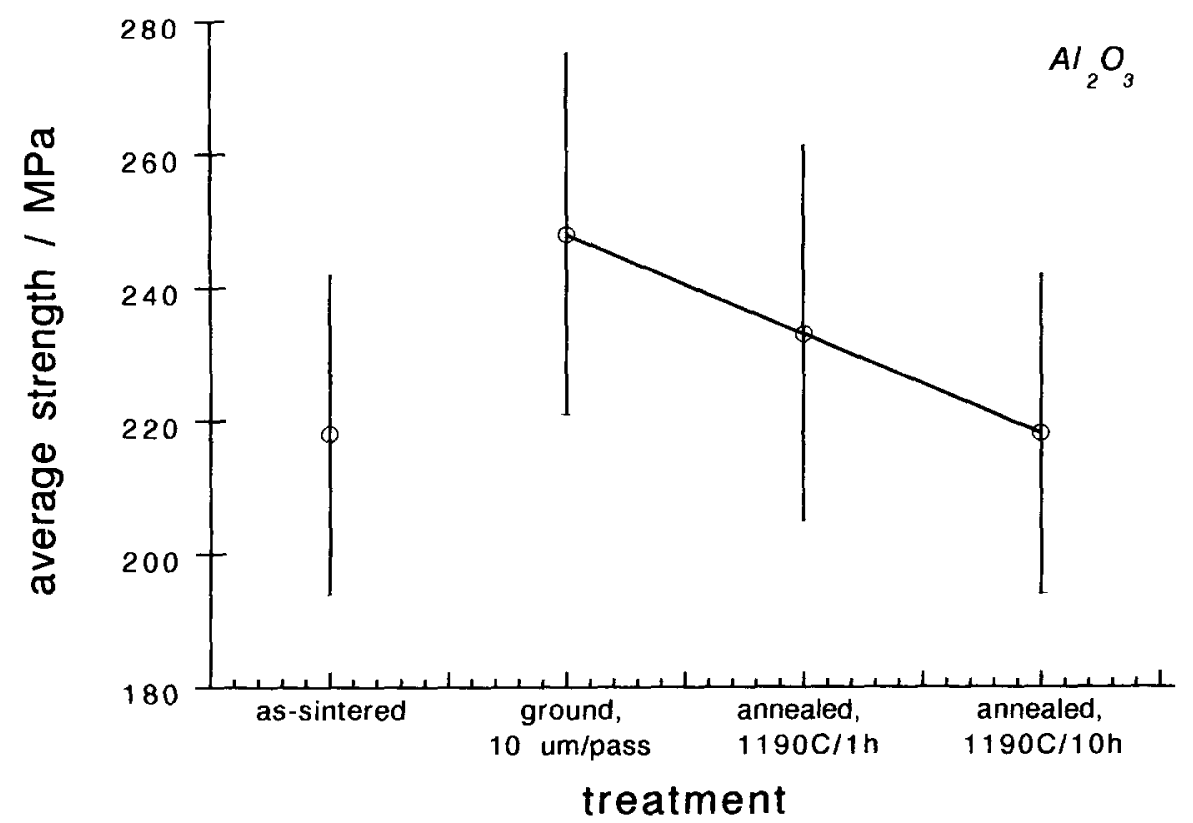

Fig. 9. The average strength of the $\mathrm{Al}_{2} \mathrm{O}_{3}$ specimens after grinding and after annealing.

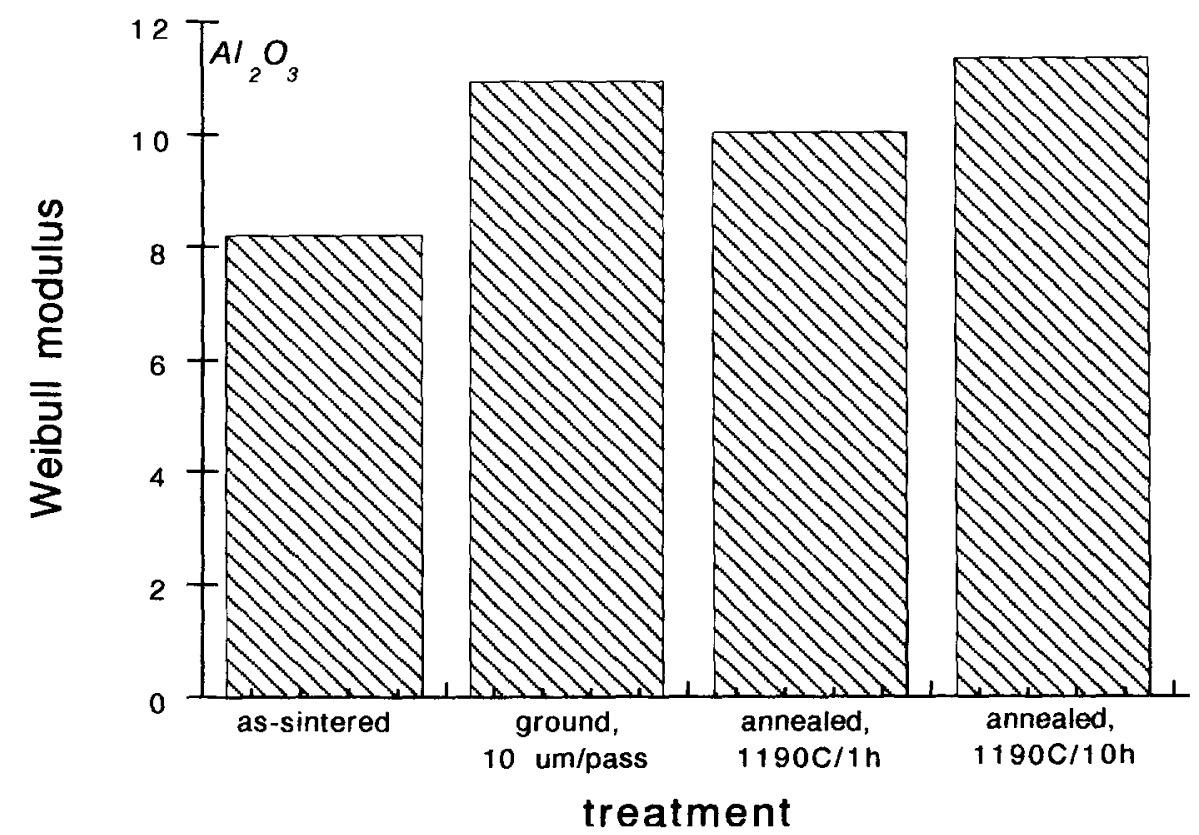

Fig. 10. The Weibull modulus of the $\mathrm{Al}_{2} \mathrm{O}_{3}$ specimens after grinding and after annealing. 
Pervious studies suggested that the crack healing process depends strongly on its temperature profile. ${ }^{25}$ As the annealing is taken place above $1200^{\circ} \mathrm{C}$, crack healing can be much more easily observed. In the present study, the annealing temperature used is lower than $1200^{\circ} \mathrm{C}$.

The difference in the Weibull modulus for the specimens annealed at $1190^{\circ} \mathrm{C}$ for 1 and $10 \mathrm{~h}$ is less than 1.5 (Fig. 10). The difference is smaller than the expected standard deviation. It indicates that the flaw size distribution is not changed significantly by the annealing treatment. It may be due to the annealing temperature used in the present study being low. The crack healing or opening process is not thermally activated. The average strength is increased as the specimens are ground, Fig. 9. As the ground specimens are annealed, the average strength is reduced by $30 \mathrm{MPa}$. This value is the same as the analysis shown in Fig. 5. It further confirms that the contribution from the residual stresses to strength is around $30 \mathrm{MPa}$.

\section{Conclusions}

Alumina specimens with surface flaws were prepared for the present study. The specimens were ground with a diamond wheel. The strength of the ground specimens was higher than that of the assintered specimens. The strength enhancement was contributed by decreasing flaw size and by introducing residual stresses. It demonstrates that the merit of applying an abrasive grinding alumina component is removal of the large processing flaws near the surface. However, the grinding parameter should be carefully chosen to avoid the introduction of machining flaws and the releasing of compressive residual stress.

\section{Acknowledgements}

The present study is supported by The National Science Council through contract number NSC862216-E002-031. The comments made by Dr S. H.-P. Li, National Taiwan University, were very helpful.

\section{References}

1. Lutz, G., Grinding advanced ceramics. Interceram., 1993, 42, 367-371.

2. Subramanian, K., Redington, P. D. and Ramanath, S., A system approach for grinding of ceramics. Am. Ceram. Soc. Bull., 1994, 73, 61-66.

3. Kanematsu, W., Yamauchi, Y., Ohji, T., Ito, S. and Kubo, K., Formulation for the effect of surface grinding on strength degradation of ceramics. J. Ceram. Soc. of Japan., 1992, 100, 768-772.
4. Marshall, D. B., Evans, A. G., Khuri Yakub, B. T., Tien, J. W. and Kino, G. S., The nature of machining damage in brittle materials. Proc. R. Soc. Lond., 1983, A385, 461-475.

5. Marshall, D. B., Lawn, B. R. and Cook, R. F., Microstructural effects on grinding of alumina and glass-ceramics. J. Amer. Ceram. Soc., 1987, 70, c-139-c-140.

6. Matsuo, Y., Ogasawara, T., Kimura, S., Sato, S. and Yasuda, E., The effects of annealing on surface machining damage of alumina ceramics. J. Ceram. Soc. of Japan, Int. Edition, 1991, 99, 371-376.

7. Xu, H. H. K., Jahanmir, S. and Wang, Y., Effect of grain size on scratch interactions and material removal in alumina. J. Am. Ceram. Soc., 1995, 78, 881-891.

8. Xu, H. H. K., Padture, N. P. and Jahanmir, S., Effect of microstructure on material-removing mechanisms and damage tolerance in abrasive machining of SiC. J. Am. Ceram. Soc., 1995, 78, 2443-2448.

9. Xu, H. H. K. and Jahanmir S., Ives L. K., Material removal and damage formation mechanisms in grinding silicon nitride. J. Maler. Res., 1996, 11, 1717-1724.

10. Xu, H. H. K., Wei, L. and Jahanmir, S., Influence of grain size on the grinding response of alumina. J. Am. Ceram. Soc., 1996, 79, 1307-1313.

11. Cho, S-J., Huh, Y-H., Yoon, K-J. and Ogawa, T., Aspects in grinding of ceramics. J. Am. Ceram. Soc., 1994, 77, 2443-2444.

12. Kibble, K. A. and Phelps, L. A., Influence of grinding parameters on strength of reaction bonded silicon carbide. British Ceramic Trans., 1995, 94, 209-216.

13. Konig, W. and Wemhoner, J., Optimizing grinding of SiSiC. Am. Ceram. Soc. Bull., 1989, 68, 545-548.

14. Rice, R. W., Porosity effects on machining directionstrength anisotropy and failure mechanisms. J. Am. Ceram. Soc., 1994, 77, 2232-2236.

15. Sornakumar, T., Annamalai, V. E., Gokularathnam, C. V. and Krishnamurthy, R., Grindability of zirconiatoughened alumina. J. Mater. Sci. Letter., 1992, 11, 10491050.

16. Tomlinson, W. J. and Newton, R. C., Effect of grinding, lapping and various surface treatment on the strength of silicon nitride. Ceramics International., 1990, 16, 253-257.

17. Kirchner, H. P. and Isaacson, E. D., Contact damage and residual stresses induced during single point grinding of various ceramics. Fracture Mechanics of Ceramics., 1983, $5,57-70$.

18. Johnson-Walls, D., Evans, A. G., Marshall, D. B. and James, M. R., Residual stresses in machined ceramic surfaces. J. Am. Ceram. Soc., 1986, 69, 44-47.

19. Srinivasan, S., Blau, P. J. and Bjerke, J. L., Effect of machining residual stresses on the repetitive impact behavior of silicon nitride. J. Mater. Res., 1995, 10, 95-100.

20. Samuel, R., Chandrasekar, S., Farris, T. N. and Licht, R. H., Effect of residual stresses on the fracture of ground ceramics. J. Am. Ceram. Soc., 1989, 72, 1960-1966.

21. Ritter Jr., J. E., Bandyopadhyay, N. and Jakus, K., Statistical reproducibility of the dynamic and static fatigue experiments. Am. Ceram. Soc. Bull., 1981, 60, 798806.

22. Service, T. H., Ritter Jr., J. E., Jakus, K. and Sonderman, D., Bimodal strength populations. Am. Ceram. Soc. Bull., 1985, 64, 1276-1280.

23. Cullity, B. D., Element of X-ray Diffraction, 2nd edn. Addison-Wesley, Reading, 1978.

24. Lange, F. F. and Radford, K. C., Healing of surface cracks in polycrystalline $\mathrm{Al}_{2} \mathrm{O}_{3} . J$. Am. Ceram. Soc., 1970, 53, 420-421.

25. Moffatt, J. E., Plumbridge, W. J. and Hermann, R., High temperature crack annealing effects on fracture toughness of alumina and alumina-SiC composite. Brit. Ceram. Trans., 1996, 95, 23-29.

26. Thompson, A. M., Chan, H. M. and Harmer, M. P., Crack healing and stress relaxation in $\mathrm{Al}_{2} \mathrm{O}_{3} . \mathrm{J} . \mathrm{Am}$. Ceram. Soc., 1995, 78, 567-571. 